\title{
Education, Consciousness and Negative Feedback: Towards the Renewal of Modern Philosophy of Education
}

\author{
Eetu Pikkarainen
}

Citation: Pikkarainen, E. Education, Consciousness and Negative Feedback: Towards the Renewal of Modern Philosophy of Education. Philosophies 2021, 6, 25. https://doi.org/10.3390/ philosophies6020025

Academic Editor: Andrew Stables

Received: 23 February 2021

Accepted: 20 March 2021

Published: 24 March 2021

Publisher's Note: MDPI stays neutral with regard to jurisdictional claims in published maps and institutional affiliations.

Copyright: (C) 2021 by the author. Licensee MDPI, Basel, Switzerland. This article is an open access article distributed under the terms and conditions of the Creative Commons Attribution (CC BY) license (https:/ / creativecommons.org/licenses/by/ $4.0 /)$.
Values, Ideologies and Social Contexts of Education Research Unit, Faculty of Education, University of Oulu, P.O. Box 2000, FI-90014 University of Oulu, 90570 Oulu, Finland; eetu.pikkarainen@oulu.fi

\begin{abstract}
Among the biggest challenges facing the contemporary human condition, and therefore also education, is responding to the climate crisis. One of the sources of the crisis is assumed to be absent-mindedness, presented by Leslie Dewart as a distortion of the development of human consciousness. Dewart's poorly-known philosophical consciousness study is presented in this paper in broad outline. The problems in the study of consciousness, the most important of which are the qualitative representations - qualia - and the question of free will, are also briefly discussed. These problems are then examined transcendental analytically, with the question of what one must assume in order to allow the emergence of these phenomena. From the resulting conception of causal relationship, we proceed to the circular causality as a prerequisite for life, namely the homeostatic systems and negative feedback. An organization of action that is essential to animals and humans is presented, using William Powers' perceptual control theory (PCT), and the role of consciousness in this organization is drafted according to the studies of Martin Taylor. Action is seen as continuous problem solving, in which negative feedback is used to bring perceptions into line with the goals. The fundamental function of consciousness is revealed as the direction and enhancement of learning. Based on PCT, it can be shown that the main practical problems in animal and, especially, human action, are related to adverse side effects of action and the resulting various conflicts. The climate crisis is a typical example of the problematic side effects of collective action. Dewart's concept of absent-mindedness can therefore be defined as an inability to responsibly account for the side effects of action. Thus, the main task of education is to forestall, through negative feedback and in cooperation with learner consciousness, absent-mindedness and the problems it causes.
\end{abstract}

Keywords: Theory of Education; consciousness; responsibility; Lesley Dewart; perceptual control theory (PCT); William T. Powers; semiotics of education

\section{Introduction}

This article is partly in homage to the woefully neglected philosophical work of the late Leslie Dewart (1922-2009). (Note that the subtitle of the article and title of the second section are adapted from his latest posthumous book Hume's Challenge and the Renewal of the Modern Philosophy [1]). However, Dewart was not a philosopher of education, and this article is not a study of his work; rather, his work forms a challenge to the development of the philosophy of education. The most important and connected challenge and background for this development is undoubtedly the pressing problem of the climatological and ecological crisis with the attendant social preconditions and consequences [2,3]. However, this article is not about environmental education, but about seeking the most basic causes of these fatal trajectories of today, and the ways they could, through education, be prevented. As an oversimplification of a very complex tangle of causes, interactions, and accidents, one might say that the coming-or rather existing — crisis is caused by human nonconsciousness and short-sightedness. We have acquired unparalleled powers to alter our environment and have used these in criminally reckless ways. In other words, the question is about irresponsibility—absent-mindedness as Dewart says. 
Dewart's main interest was the phenomenon of human consciousness and its development [4]. Human consciousness develops with the appearance of human speech as a tool for assertive communication of experiences. This aspect of language makes it possible to experience, act and communicate consciously. For some reason, consciousness seems to have developed in a certain way defectively in our Western cultures, and it creates the state of mind which Dewart calls absent-mindedness. We do not conceive of, or understand, our own consciousness accurately. In his final, posthumous work, he directs us to an analysis of the history and stagnation of modern philosophy; and as a remedy to the problem of absent-mindedness, he requires that philosophy develop our practical wisdom to live without damaging ourselves, our neighbors, and the whole planet. In a word, philosophy should teach conscious human living. Because it is through education, rather than plain philosophy, that people's consciousness is generally raised this task belongs particularly to the philosophy of education. This branch of applied philosophy should develop a theory which can help us understand how education functions and, furthermore, help us choose the aims of education.

The starting points for the development of the philosophy of education in this article are, in addition to Dewart's theory, action theoretical semiotics-or semiotic theory of action-developed by the current author (see [5,6]), and, in particular, the theory of perceptual control (PCT) initiated by William T. Powers [7]. The most important conception of action theoretical semiotics is the insight that meaning is connected to action (The concept of action is understood here in the "continental" meaning (cf. Handlung) as intentional or purposeful total activity of a subject in relation to the environment. Action can contain both the observable external side which affects the environment and the unobservable internal side which can be understood as processing the sense perceptions and planning of external action or deeds. Traditionally this concept is strongly differentiated from the concept of behavior (of behaviorism) as exclusively observable activity. In the PCT tradition the parlance is often the other way around, so that behavior means "all that happens in a subject" and action means "just the external deeds."). The meaning of whatever event, object, expression, or anything else is the relation of that whatever to the action of the subject who experiences that meaning. Another central notion is the Greimassian concept of competence as a peculiar property of the subject which makes it possible for that subject to act in the way it does (pp. 44-46 in [8]). The birth of PCT in the middle of twentieth century was based on Powers' brilliant realization that the behavior of human- and all living- beings can be understood as negative (Here negative does not mean any negativistic attitude or bad consequences but instead rather well-meant measures to prevent the detrimental effects of any disturbances which would push the controlled perception out of the actor's goal) feedback or purposive control, and even accurately modelled and explained with the mathematical tools of servomechanism. The concept of control, here, means simply that the actor tries to affect things so that it perceives what it wants to perceive.

In order to understand the forms of learning and how they can be enhanced and directed by teaching, we must consider the existence of living beings and the function of learning in their life processes. Life can be essentially seen as a negative feedback system which manifests itself initially as homeostatic mechanisms and later develops into perceptual control. Learning can be seen as the reorganization of these processes in individual living beings, which takes place in the context of their generational evolution and then, later, in their cultural development. Alternatively, homeostasis means (roughly) the genetically-determined, biochemical mechanisms for maintaining stable conditions inside an organism. Perceptual control, in distinction, uses senses, nerves, and muscles to affect the environmental conditions. The latter system has developed via evolution to help and protect the earlier system from variable and hostile environments. The functioning of this perceptual control system is what we call action in the previously described sense. In action-particularly human action-there are two important and well-known practical problems: side-effects and especially conflicts. These problems should in principle be repaired in time by reorganization or evolution, but nowadays they seem to form an ever- 
growing threat to the whole existence of human beings. A crucial threshold in evolution, according to Dewart, was the birth of a human consciousness which should have helped us avoid these kinds of problems, or helped forestall them, but because of our absentmindedness the current use of consciousness has, instead, escalated those problems. Thus, it is quite easy to infer that enhancement of responsibility in relation to the side-effects and possibly caused conflicts should be one of the central aims of education.

In Section 2 of this paper, Leslie Dewart and his philosophical theory about the development of human consciousness and its problematic form of absent-mindedness is introduced superficially and in broad outline. Then, in Section 3, the current philosophical and scientific research of consciousness and its central questions are discussed briefly. The two most important questions for the context of this article are those of qualia or the qualitative representations or impressions as central constituents of consciousness, on the one hand, and the connection of consciousness to the problem of free will, on the other hand. In Section 4 the conditions of the possibility for consciousness and free will are sought. This means a transcendental analytic (in a Kantian way) question of what we must assume about the basic elements of reality for the emergence of consciousness and free will—and life — to be possible and understandable or explainable, and not ascribed as a miracle. This analysis takes place at the level of basic, causal relationships. In Section 5 the special case of causal relations, namely circular causation, is presented. If the causal interaction in this kind of loop happens to take place in a special way (i.e., a negative feedback), then the loop forms a homeostatic system, which is the basic constituent and form of all living beings.

The perceptual control loop as an evolutionary adaptation of homeostatic systems is introduced in Section 6. The special features of perceptual control are its ability to affect purposefully the environment of the organism and its ability to learn or reorganize. What we call action of animals and humans takes place mainly, or wholly, by perceptual control. The main practical problems of individual and, especially, collective control of perceptions, are side-effects and conflict. These are considered in the Section 7. In the penultimate Section, we will return to the main questions of consciousness. Briefly, the main function of consciousness is to act as an internal teacher who, on one hand directs learning via negative feedback to those parts of the organism where it is needed and, on the second hand, plans new ways to act. In Section 9, the final Section, some conclusions for education are made.

\section{Dewart's Challenge: Human Consciousness and Absent-Mindedness}

Dewart is best known from his earlier career as an eminent Roman Catholic philosopher of religion in Canada. His most influential publication at that period was The Future of Belief: Theism in a World Come of Age (1966), which made him one of the most debated radical theologists of anglophone Catholicism [9]. Later, he turned to more secular topics (The development of Dewart's thinking seems to have started from the program of dehellenization of theology [10], leading to demythologization and to the naturalization of philosophy and abandonment of theology). He completed a degree in law and also worked as a practicing lawyer in the 1980s. During this period, he wrote his philosophical masterpiece Consciousness and Evolution: The Role of Speech in the Origin and Development of Human Nature (1989 [4]). In this book Dewart builds a complex and detailed argument about the development and nature of consciousness as a distinctly human feature.

Next, I will very shortly condense the main results of this book, following his own synopsis [11]. Dewart stresses that consciousness is a fully natural and historically-developing feature which cannot be reduced to biochemical processes of the brain, despite these processes being the cause of consciousness (p. 14 in [4]). He describes the emergence of consciousness as a new way of using those same biochemical processes which we share with animals and which make experience possible. All animals can experience but only humans can experience consciously (The concept of consciousness, for Dewart, means specifically a human feature which requires the development of human speech. This denial of animal consciousness sounds unnecessarily stark, and it is not so strict in his later book. 
It is best interpreted as Dewart's interest in the human form of consciousness and not in the possible animal forms. Later, I will state that animal consciousness is a precondition for the human consciousness). Conscious experience means that the experiencing subject not only experiences the object of experience but also experiences the process of experiencing and herself as the experiencer. Thus, in conscious experience, the act of experience is present to itself: the experience, in other words, is self-present. This simultaneous consciousness of these different parts of experience must not, however, be mixed with self-observation or self-reflection (In philosophical discussions this kind of human consciousness is often called self-consciousness. When Dewart denies that he means self-consciousness, he actually concurs with Henrich's $[12,13]$ and others' criticism against the vicious circularity of the theories where self-consciousness develops so that the subject or her consciousness takes itself as its object).

The ability of conscious experience and action is not a consequence of evolution as genetical natural selection, but of a certain new way of human action-namely, speaking. According to Dewart, human speech differs from animal communication because of its assertiveness. By this he means that the communication is intentional: that is, that the speaker intends to communicate her experience, and experiences this very communicating as a causal process. It is important to note, here, that historically, speech develops before consciousness and then after this, develops the languages. This same sequence must somehow be repeated in the development of every child. What is distinctive is that Dewart does not say that the structures of the languages would condition our thinking and action; he says that it is the way around: the way we have learned to speak has formatted our consciousness and then, also, languages. A central part of the process of development of speech is the ability to speak thematically by connecting a thesis to a theme in sentences "asserting a thesis in relation to a theme" (p. 78 in [11]).

The genesis of consciousness means also, inevitably, the rise of existential questions about birth, life, and death and, thus, the birth of religion or at least of the sacred. The past and current ways of human living — cultures broadly speaking-have not developed by biological evolution but by conscious living and by building institutions of conscious life. The development of consciousness is not an all-or-nothing question, but it is itself a developing feature and it forms its own area and type of evolution which will continue also in the future. However, the development of consciousness can, like any other evolutionary process, take a more or less adaptive or maladaptive course. One of the most interesting and challenging parts of Dewart's theory is his view that in the early history of humankind a certain human population-the ancestors of our western culture-realized the process of initial creation of consciousness in a specifically defective way. The defect in this process was its partiality, so that the subjective part of the process of experience-the subject's own activity-was not conceived properly.

That regrettable partiality of consciousness has had many remarkable consequences. One consequence that Dewart uses as a part of his argumentation is the special thematic structure of the Indo-European (and Sumerian) languages, which he claims to be different from all other known languages (This is a controversial hypothesis which is extremely difficult to test empirically. However, it is one viable explanation why just we Westerners have managed to produce so many chains of new solutions to the problems created by previous solutions, and why non-Westerners have had so much difficulty in following us). This difference culminates in the Indo-European use of a copula verb in the sentences like " $X$ is $Y$ ", whereas others say just " $X Y^{\prime}$ ". Dewart argues that the form of the first expression stresses the existence of an external reality - an objective structure that insists that $X$ has an active power to be $Y$. The latter expression, in distinction, stresses the fact that it is the speaker who connects $\mathrm{Y}$ to $\mathrm{X}$ in her experience and assertion. The same verbal structural difference is visible also in other kinds of sentences, but not so strikingly. Semiotically this difference could be formulated so that the latter structure, which is based on the more profound and sound conscious experience, is a case of "meaning making" [14], whereas the previous one is "meaning receiving". Dewart uses a term "absent-mindedness" to 
depict this partial and defective consciousness. This stance resembles certain kind of irresponsibility, because the subject of the experience/assertion does not take and feel the full responsibility of her own assertion, but instead transfers the responsibility to the object of the experience (Gregory Nixon calls this phenomenon that has made both religion and science possible "objectivity sickness" (in personal communication). Of course, also non-Westerners have religions and sciences, but they have been quite different from ours).

An absent-minded experiencer/speaker does not cognize that it is herself who is asserting, but instead feels that it is the reality speaking to her. This causes a certain kind of religious stance which easily and logically develops into a view that there is some more or less personal Power who is speaking through reality to us and, by its assertion, determines reality and our fate. Because the absent-minded person cannot fully empathize herself, she also cannot respect the humanity in other persons. And because she projects her own causal activity to the transcendent Being, she cannot see any other possibility than worshipping the more or less absolute Power. About our modern Western secularization, Dewart says that instead of Power, we have (nowadays) only started to worship power, which is still worse (p. 341 in [4]; p. 83 in [11]).

Dewart's diagnosis is that our absent-minded orientation to our environment and fellow people causes necessarily recurring problems and conflicts. The institutions of our conscious life (religions, sciences, and philosophy) that should and try to solve these problems are likewise captives of this same defect and make their solutions ineffective to their ends. The use of power is too easily seen as the only tool for resolving human problems - problems which are often originally produced by the use of power.

After publishing Evolution and Consciousness, Dewart hoped to study in greater detail the "topic of cultural neurosis of Western civilization" [11]. At this point, he directed his attention to what is probably the most central institution of the conscious living in modern society: namely, philosophy and, more particularly, to the history of philosophy. Philosophy is not free from religion in the Dewartian sense (i.e., of asking the most basic existential questions), but it seems that he had lost his faith in the possibilities for reforming institutionalized religions, so that they could lead the way to healthy conscious living. This responsibility to lead the way to the development of conscious living belongs now to philosophy. Much to Dewart's disappointment, however, its development seems to have stagnated long ago. Dewart tries to trace in a very detailed manner the chains of events which eventually led to a long period of stagnation. Unfortunately, he did not have time to finalize the work before passing away in 2009, but fortunately his family asked his old friend and student to edit the remaining manuscripts to a book which was then published as Hume's Challenge and the Renewal of the Modern Philosophy in 2016 [1].

In a nutshell, the context and the roots for the origin of philosophy was in the ancient Greek religion and its belief in the faceless. omnipotent and cruelly capricious fate (pp. 112-114 in [1]). The continuum of philosophical arguments and, of course, also the new Christian religion, tried to develop consecutive conceptual solutions to this basic problem - and every time created new conceptual problems. Towards the end of the Middle Ages, the whole fine enterprise disintegrated into existential skepticism: Philosophy was no longer even able to confirm the existence of reality ([1], p. 178). Descartes' attempt to recreate philosophy from the new beginning was doomed to failure, because he did not know the history of the situation and, finally, Hume drove the scandal to its culmination. The core problem is what Dewart calls representationism (pp. 31-40, 177 in [1]). The term refers basically to the idea that cognitions exist independently in the mind as representations or copies of the intelligible contents of their objects in the reality. This 'double existence' causes skepticism about the reality of the latter. Modern philosophy tries to reject skepticism but accepts representationism; stagnation is the logical result (p. 67 in in [1]).

So much for the problem: what, then, is the solution? Dewart dreams of "an empirically sound philosophy of the future" (p. 205 in [1]) and believes that "once we understand the defects that have hindered philosophy, and how they came about, the reconstruction of the discipline should be set in motion with an attempt to revise the traditional assumptions 
of cognition, causality, and reality in order to align them with what experience reveals" (p. 228 in [1]). We will not follow him further, here, but start to move towards the problem of consciousness and its relation to education and keep in sight his teachings.

\section{Problem(s) of Consciousness}

"What is consciousness?" should be an easy question because all we know-in a classical sense as justified or reasoned (hopefully) true belief-we know in, or through, our consciousness. Still, consciousness is often regarded as a most tricky subject of research, if not even a mystery. A major reason for this is, of course, that consciousness is to some extent a subjective phenomenon. Everyone has his or her own consciousness, and a skeptic can even suspect the existence of the consciousnesses of others. In addition to this restricted private accessibility, the phenomenon of consciousness seems essentially qualitative and effectively resists quantification. We cannot easily measure numerically even our own consciousness, let alone achieve objective measurements of consciousness, generally. Thus, consciousness really seems unsuited to any scientific research. Progress in the philosophical study of consciousness, from the time of Aristotle or even Descartes, has also been quite unimpressive-as Dewart was at pains to demonstrate. The points of view of researchers differ wildly.

A special modern peculiarity has been the wholesale denial of the existence of consciousness. Galen Strawson refers to that movement as "a long training in absurdity" [15]. The starting point for these attempts is, undoubtedly, the notion that the phenomenon of consciousness does not conform to the modern physicalist world view. Clearly, this kind of thinking is an example of the absent-minded denigration of lived experience. Nothing should be more securely known and experienced than our own consciousness. Surprisingly—or perhaps not-this movement has been popular among philosophers, but not so much among physicists, who think like Strawson himself that consciousness is somehow a more important constituent of the world than those features which are revealed by physics.

There are many rupture lines in the study of consciousness. One is about who, or what, is or can be conscious. Some think that only human-beings are, or can be, conscious (for example Dewart of [4]); others, that humans and higher animals (for example Dewart of [1]); then others state that possibly all animals $[16,17]$ (Chittka \& Wilson present compelling evidence that, for example, some social insects like bumblebees indicate such creative and elaborated problem-solving that it is impossible to explain it without assuming some kind of conscious consideration); and, finally, those that take the broadest possible scope by saying that all physically-existing matter is conscious or even consists of consciousness [18] In these differences lurks the old dilemma of the relation between mind and matter-and thus the alternatives of materialism, idealism, and dualism. Idealism and dualism are not in fashion today, and scientifically oriented modern people usually try to present the ideas in the form of some kind of materialism or physicalism; nevertheless, dualism and idealism have a strong lure - an attraction which Dewart criticizes. A remarkable protagonist of the recent study of consciousness, David Chalmers, represents what is called "property dualism" (p. 124-125 in [19]), an idea that claims that though all real substance was material, and the properties of that substance were generally material, too, consciousness is still somehow a non-material mental property (I must admit, it is difficult to understand how a property would be either material or not). This connects further to the question of free will and epiphenomenalism: can consciousness affect our material action? Is consciousness free or determined? Or is it just an epiphenomenon that passively reflects material goings on? For Dewart, it is consciousness itself which can enable our human freedom (p. 257 in [4]).

But what kind of property is consciousness-or, what kinds of properties does it have? The most generally accepted property or character of consciousness is something which has been described with the concepts of quale or the "what it's like" feature (See, however, a critical stance in [20]). These qualia or the qualitative experiences or feelings are just those which fulfills my experienced world, and I assume that the world you experience 
also consists of more or less similar qualia. The experienced blueness of the blue sky that I am watching in the evening is a quale. Likewise, the pain I feel in a cramped muscle is a quale. However, we cannot compare our qualia, we cannot even be absolutely sureby evidence- that others have qualia at all. This problem leads to the famous zombie hypotheses [21]. The philosophical zombies are unlike those in horror movies, at least by appearance and behavior. Actually, if you were to meet one, you could not even know it is a zombie because it seems and behaves just like an ordinary person. The only difference would be that it does not have any qualia and therefore any consciousness. If zombies exist, it means that consciousness is unnecessary and an epiphenomenal surplus luxuryor burden. However, can they exist? A closely related question is whether the highly developed artificial intelligence of the future will have consciousness.

But what are qualia, and why do they exist? I will next try to search for the answer from a somewhat different starting point, with inspiration from the ontological theory of John Heil [22]. This approach to ontology could be called "transcendental analytic" in the sense that I will search for the conditions of the possibility for the phenomenon of consciousness. By these conditions of possibility, I mean in practice the most basic assumptions we must make about reality in order for existence of consciousness to be possible and understandable (What is extremely important in these assumptions is that they are as much as possible compatible with the results of modern science; they are not just imagined. This is a central requirement also in Dewart's program).

\section{Causality and Panexperientialism}

I start this section from what might be considered an extremist view: namely, the afore-mentioned Strawson's panpsychism. On many occasions Strawson has staunchly defended the seemingly paradoxical statement that true materialism entails panpsychism [23]. Panpsychism claims that all concrete reality consists of consciousness. Materialism, for Strawson, has the same meaning as physicalism, but he strongly separates physicalism from what he calls "physics-alism" or the doctrine that claims that science of physics can capture the whole essence of all reality [24]. There are at least two arguments for his view. Let us call the first a no-miracles argument and the second an epistemological argument. I will next consider them both.

The no-miracles argument is built against (radical) emergentist views, which say that consciousness is a novel emergent phenomenon which emerges and supervenes over suitably complex non-conscious physical reality. Strawson does not accept this kind of radical emergence, because it is unintelligible. It is hard to believe that from something non-conscious could emerge something conscious-or, in Cartesian terms, from extensible could emerge thinking reality [25]. That is why we must assume that the reality must be at least somehow conscious already from its simplest appearances. The qualification "somehow" is, of course, essential. The most important condition for emergence is, however, the structure. From simple elements can emerge something novel, but only if the elements form a novel structure. A simple example would be a vault made of bricks. Bricks are hard and impenetrable but when stacked up in a special way they manifest a novel emergent property of the vault: namely, its penetrability. The bricks do not need to be penetrable. Their hardness and the novel structure of their interrelations are enough to make the emergence intelligible.

The other argument for panpsychism, which I call epistemological, is connected to the famous "knowledge argument" against physicalism [26]. The idea of the knowledge argument is basically this: Because physical sciences cannot tell what it is like to have qualia, for example, to feel pain or see the blue of the sky, then either physicalism is not true-or qualia has nothing to do with knowledge. Strawson's reply to this is the aforementioned point that physical sciences can describe only structural and quantitative features of reality but not its essence. At bottom, reality is qualitative and accessible to our consciousness, because "consciousness (psyche) is present in all (pan) reality [27]". Here too, I think that Strawson goes too far, because first, it does not require consciousness for something to be 
qualitative. It is enough that there exists the identity of powers and qualities in properties (pp. 111-115 in [22]). Secondly, as Dewart stresses, we should not assume that reality is intelligible as such, in the same ways as consciousness necessarily is by its nature (see, for example pp. 90, 140, 150, 336 in [4]). In this sense panpsychism would rather mean classical idealism, instead of materialism or physicalism.

What, then, does it require from the simple elements of reality, for the emergence of consciousness to be possible? I attempt to depict these basic requirements in Figure 1. The circles represent physical beings that can be more or less simple or complex, and which have those powerful qualities, or dispositions, to affect other beings and be affected in turn. These effects can be qualitatively and quantitively different, depending on the participants' dispositions and overall conditions. The basic assumption is that all beings affect all other beings, but the effects can be minimal to beings which are either distant or very irresponsive because of their dispositions. These effects are depicted as arrows. In the figure, being A affects being B, so that some of the properties of B change, more or less. A simultaneous, but contrary, effect occurs from $B$ to A. These reciprocal effects need not be similar: What properties change and how much they change depends on the qualities and quantities or strengths of the effects and on the dispositions of the beings themselves.

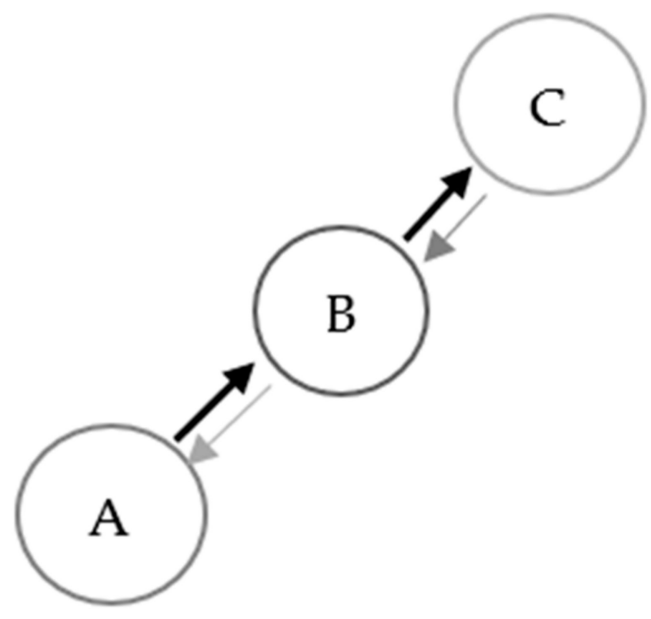

Figure 1. Physical beings A, B, and C affect each other, with qualitatively and quantitatively variable effects. Being A strongly affects and causes some change in B; the changed B affects respectively C. The oppositely directed effects are thought to be weak and can be ignored, as with all other possible effects between these and surrounding beings.

When A affects B, the latter undergoes some kind of change: some of its properties will be different because of that effect. If we define experience as an event wherein a being encounters another being, and the effect of this encounter causes some more or less durable change in the first one, then we can say that B experiences the effect of A. These simple beings seem to have an ability to experience qualitatively and quantitatively different experiences. Thus, unlike panpsychism, panexperientialism (This view has also been called, e.g., panprotopsychism [28]) does not entail idealism [29]. Of course, we should be careful of anthropomorphism, because these beings cannot have meaningful experiences. Meanings require that the experiencer be a competent subject of action with a purpose. These beings have no purposes of their own-they are just as they are, from moment to moment.

In addition to experientiality, we can attribute some other interesting abilities to these beings. Firstly, the changes which the A's effect causes in B depend not only on A and its forces but also on B itself, its condition, and its own dispositions. So, we can quite reasonably say that A interprets B's effect. And further, when A's effect changes the way $B$ affects $C$, we can say that $B$ communicates its experience or at least part of it to $C$, can we not? Again, communication must be understood in a narrow and technical meaning as mediation. No meanings are communicated, and while Dewart states that 
human consciousness starts to develop when a human being communicates her experience assertively to another human being, with an intention to communicate it, there are no intentions in play and, therefore, no consciousness develops in this level-at least not in the Dewartian sense.

Two lessons should be taken from this consideration. The first is that the emergence of consciousness and many more modest phenomena of life (e.g., purposes, intentions, meanings etc.) in complex structures in these kinds of simple, nonliving, and unconscious beings is no miracle but quite understandable and, at least in principle, explainable mechanisms. The second lesson is connected to the problem of freedom and determinism. There is no need to postulate absolute determinism - the notion of being governed by some transcendent or transmundane "laws of nature" - which Dewart sees a modern version of ancient belief on fate (e.g., p. 333 in [4]). The beings determine themselves by their own character. They respond to effects as they do because they are as they are. "Since the world is heterogeneous, causal regularities do not imply absolute determinism even in the case of inanimate causation, though the invariability in the latter form of causation is, for all practical purposes, equivalent to determinism" (p. 262 in [1]).

\section{Negative Feedback and Homeostasis}

We already saw that, in principle, all interrelations between beings are interactions. Next, we must take a look at a very important special case: namely, circular interaction. We will continue with our familiar beings $A, B$, and $C$ and just think that they form a circle so that $C$ affects $A$ as in Figure 2. The essential idea is that $A$ affects $B$ in a way which changes $B$ 's effect on $C$, which respectively changes $C$ 's effect back to $A$. In a way, A receives from $\mathrm{C}$ the consequences of its own effect on B back, and that is why these kinds of circles are called feedback loops. For the sake of simplification, we will ignore the possible qualitative differences and consider only the quantitative differences between the effects and their consequences. A's effect on B can be stronger or weaker and it can cause B's effect on C to be stronger or weaker, and so on. If A's effect on B increases the strength of B's effect on C, we say that A's effect is positive or excitatory and, in an opposite case, we call it negative or inhibitory.

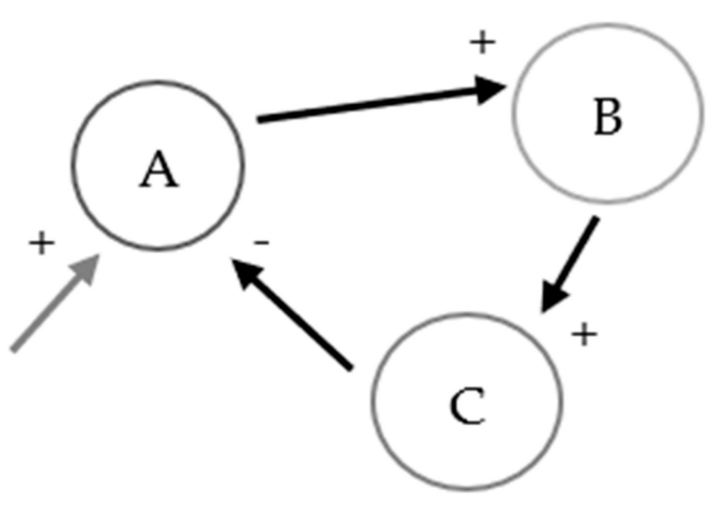

Figure 2. In this negative feedback loop physical beings A, B, and C affect each other circularly in this order with quantitatively variable effects. All other effects are ignored in this figure except one variable effect from the environment to A which can disturb the balance of the effects in the loop. The plus sign means excitatory and minus inhibitory effect. The external disturbance strengthens A's effect, which strengthens B's effect and, further, C's effect; but C's now stronger inhibitory effect weakens A's effect, returning it to the original level.

In sufficiently ideal conditions this kind of dynamic system can be more or less durable and remain more or less in a balance. From this arises the following critical question: What happens if the balance of the effects between the members of the circle is disturbed? Let's imagine that some external being causes an excitatory effect to A, so that its effect on B becomes stronger. If all the effects in the loop are excitatory, the consequence is what could 
be called a positive spiral, with all the effects acceleratory increasing until all usable energy is wasted or the structure exploded. This process is called positive feedback. However, if there is a suitable combination of excitatory and inhibitory effects, then it is possible that the negative feedback effect from C to A will return A's effect to B back to its original level. Thus, a negative feedback loop can maintain its balance, which means that it functions as a homeostatic system (This extremely simplified description is based mainly on [30], and I suggest checking the details there, when that ground-breaking book will be published).

The birth of the first relatively stable homeostatic system was also the birth of purposiveness in the physical world [31]. All homeostatic systems can not necessarily be called living beings, but all living beings are essentially homeostatic systems as a whole, and they consist of varying amounts of more or less complex and interacting networks of smaller homeostatic loops (see Chp. 18 in [32] and Chp. Homeostasis-Maintenance of A Nearly Constant Internal Environment [33]). The purpose of a homeostatic system is its own homeostasis, the maintaining of the dynamical balance (Michel Serres suggests the term homeorhesis (and homeorhetic) (p. 74 in [34]) coined from homo = same and rhysis = flow rather than homeostasis because the balance is dynamic and variable, flowing, and not static), or the self-preservation of the system, which all are the same thing. This is what it is striving for, and now we can start to talk about meanings and meaningful experiences-but not yet consciousness.

In living organisms, like a human being, the homeostatic systems ensure that the critical variables-like temperature and sugar and oxygen levels etc.-remain in stable or context-dependent suitable values in the internal environment of the organism. This activity requires that there be a stable enough flow of high energy raw material into the internal environment of the organism and of low energy (entropy) waste material out to the external environment. Thus, these systems do not quite have an ability to manipulate the external environment. This ability for action proper requires the next level of emergence: namely, the appearance of perceptual control along the development of nerves, senses, and external effectors, mainly muscles (Antonio Damasio connects his new approach to consciousness similarly to homeostasis and interprets that "optimal ranges [of the critical variables EP] express themselves in the conscious mind as pleasurable feelings; dangerous ranges, as not-so-pleasant or even painful feelings." (Chapter 2. From Life Regulation to Biological Value in [35]; italics in original). However, the missing level and conception of the control of perception makes his analysis regrettably abstract).

\section{Action as Control of Perception}

Control of perception, which is the constitutive character of the action of human beings and actually all animals, is a special—and in principle an astonishing simple—case of homeostatic or negative feedback loops. It consists generally merely of bundles of nerves (A control system does not necessarily need to be based on nerves. Instead of nerves, there could be anything else which just functions similarly enough and is able to mediate effects. In animals and humans these systems are mainly based on nerves) and certain synapses as connections between them; but it is perhaps easiest to approach it from a slightly more complicated case of what is called the basic level loop, which also contains the sense organs and some effector organs, typically muscles. Figure 3 depicts the structure and basic constituents of this kind of loop. There are three necessary functional constituent "beings" or parts internal to the organism, and they are called input function, comparator, and output function (The term "function" is to some extent polysemy. It means, on the one hand, the task or the effect of an organ in the broader activity of an organism; on the other, a mathematical function which transforms the input values to certain output values in a consistent and mathematically describable way. Both meanings apply here). Then there are two parts which reside at the borderline of the organism and its environment, namely the sense organ, which receives effects from the environment and the effector organ, which sends effects to the environment. Finally, there must be a more or less complex environmental 
part, which is usually called the feedback path but which we will now simply call an object. (p. 28 in [36])

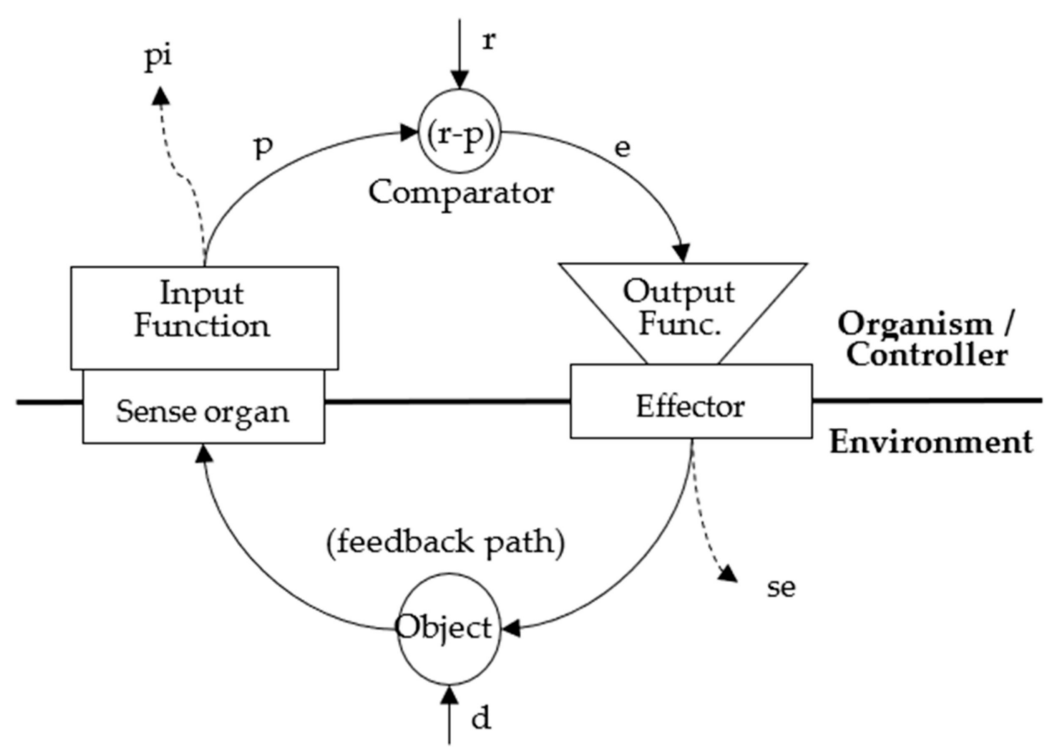

Figure 3. A simple basic level control loop has these parts and functions: An external Object in the environment affects the the Sense organ, which, together with the Input function transform the environmental effect to a perceptual signal (p). Then the Comparator (function) compares the perceptual signal $\mathbf{p}$ to the reference signal $(\mathbf{r})$ and sends their difference $(r-p)$ as an error signal (e) to the Output function, which, together with an Effector organ, converts the error signal into an environmental effect towards the external Object. The $\mathbf{d}$ arrow is a disturbance effect which throws the system off balance and thus causes the strengthening of the error. The effector's operation tries to cancel the disturbance and return the system back to balance. The dashed arrow se means side-effects, and $\mathbf{p i}$ is a perceptual signal to somewhere else in an organism.

The interaction between the three internal functional parts of the control loop takes place via one-way nervous signals. The input function (together with the sense organ) creates a perceptual signal, perception (In PCT the term perception means only such a neural signal which is produced in an input function. It can be originated in sense organs, but it is not necessary, because it can also come from the memory. The latter case can be referred as imaginary perception. It is very presumable that real perceptions are often combinations of these two types. However, it is important to stress that these perceptions are not conscious, as such) and sends it to the comparator function which also receives another signal, reference, to which it compares the perception. If these signals are similar enough, then that system is in balance and no changes occur in its functioning. However, if there is discrepancy between them, then the comparator generates an error signal whose strength is the difference between perception and reference. The error signal is sent to the output function, which channels it in a specially-governed way to the effector organ (p. 92 in [7]). The effector organ-typically a muscle-then affects the environment in which the being exists, who is at the same time the object of that effect and the object of the sense perception. In a finer analysis, the object of muscular effect is not necessarily a solitaire being, but a chain of interacting beings like in the Figure 1-thus the name feedback path. And respectively the object of perception is finally the being in the end of the feedback path. However, it is not that being as a whole, but one property of that being which is "communicated" to the sense organ. In this sense it can be said that a perception corresponds a certain property in the environment.

The interesting case is when the system is out of balance because of the discordance between the perception and the reference. Theoretically we say that this discordance is caused by an external disturbing effect to the object, and the system tries to maintain the 
balance by affecting the object in such a way that the disturbance would be cancelled. So, the system controls its perception by affecting its object, and the goal for its action is to get a perception which matches with the reference. "When you do something, you do what you do in order to change or maintain your perceptions. (p. 22 in [37])" It is important to note that the system does not, and even cannot, control its output and effect on the object-contrary to many traditional theories of action. How can it then know what and how it must do? It can know what to do, and how, only because it has learned it in its individual history or in the evolutionary history of its species. It is quite usual that its skill in affecting the object is not perfect, and that it accidentally also causes other effects in its environment. These other effects are the (primary) side-effects, depicted with a dashed arrow in the Figure 3.

Another important question arises: Where does the reference signal come from? The first answer to this is that in living beings it is always generated inside the organism, while in engineered control devices, it is caused and determined outside the system by the designer or the user of the device. That, precisely, is the most important difference between living and non-living systems. The second answer is that it comes from the same place where the other dashed arrow (pi) in Figure 3 goes. That instance is not a homunculus but instead just another control system or a bunch of them. It is clear that an organism, like a human being or an animal contains very many perpetual control systems, simply because we have so many sense organs and muscles. Skillful action requires, of course, a coordination in the activity of the separate muscles, and this coordination is assumed to be done by hierarchies of similar simple three-part control units. This hierarchical structure means that the total amount of control units is a multiplication or, rather, a quadruplicate of the amount of the basic level units.

In a control hierarchy one higher control unit governs many lower-level units by receiving their perceptions to its input function and combining them to a new perception. It then compares that new perception with its own reference. Finally, it processes the possible error signal in its output function and sends it back to lower-level units as their references. The more the organism has complex perceptions-objects of action, goals of life-the more there must be these hierarchical levels (p. 102 in [7]). The hierarchical organization of the control units can be said to form yet another emergence level which produces "intelligent behavior", a flexibly adapting versatile action, which—despite the scandalously disparaging view of Descartes about animals-does not look automatic or mechanical. However, it must be stressed that even this kind of skillful action does not yet, as such, require or produce consciousness.

How does the hierarchical system know what kind of perceptions and what kind of references are useful for the overall success and self-preservation of the organism? Again, only two ways: from trial-and-error in learning and through evolution. In the case of human beings and other complex beings with a long helpless childhood (or juvenile stage), mainly from the previous; and in the case of simpler and quickly maturing animals, like insects, mainly from the latter. The fact that adult human beings can control so many and so different perceptions, is evidence of the incredible adaptability and plasticity of our nervous system. The process where the nervous system builds new hierarchical control systems, learns to perceive wholly new perceptions and old perceptions differently and control them better and in new ways is called reorganization in PCT (p. 187-190 in [7]). In semiotic terms, it means a development of semiotic competences to recognize and differentiate perceptions on the one hand, and on the other hand a development of operative competences to control these perceptions by affecting the environment in different ways.

\section{Side-Effects and Collective Control}

Two extremely important and interesting phenomena connected to perceptual control are the side-effects and the collective control. These-also interconnected-phenomena mean on the one hand serious problems to control and on the other hand great possibilities. The problematic side of the collective control is the possibility of conflicts. However, let 
us start to disentangle this complex from the concept of side-effect (Side-effects are often mentioned but seldom studied systematically in PCT. A remarkable exception is [30]). I would like to first differentiate primary and secondary side-effects. The primary side-effect is depicted with the dashed arrow (se), in Figure 3, and it is usually a problematic or even damaging phenomenon because it means a waste of energy. A side-effect is an effect which the controller causes, and which should affect the object in a right way, but instead affects something else. A good technical example is the incandescent bulb, invented by Edison. It is meant to produce light, but most of the electrical energy is wasted to produce heat. Even that side-effect is not so harmful if the waste heat is needed to warm of the house. However, now we have developed led lights, which produce less heat as a side-effect.

Another illustrative example of harmful primary side-effects is that of the crying of a baby. A baby does not have many other ways to control its perception of bad feeling than by crying. If the mother or someone hears the cry, she can help; but if no one hears or no one can help, then the energy of crying is wholly a primary side-effect: just wasted energy, which usually makes the baby feel worse because of growing hunger and rising warmth-not to mention the frustration of a continuing error situation (This also an example of positive feedback loop). This is also a good example of the phenomenon that reorganization - and evolution in a longer time scale-tends to reduce side-effects by developing more effective operational competences. The primary side-effect is, in principle, always a greater or lesser failure of the control; nevertheless, it can still sometimes have also useful consequences, especially in collective control, if some other controller happens to benefit from them.

Secondary side-effects are unintended consequences of successful control. If you buy the last loaf of bread from the shop, you can successfully, with minimal primary side-effects, control your perception of hunger; but the secondary side-effects may be that the next client cannot control her hunger, so the shop keeper has to phone to the bakery and order more bread, and so on. These side-effects can mediately affect your future action but not necessarily-it depends on conditions. Similarly, like primary side-effects, these can be also either useful or harmful —or perhaps meaningless. However, our critical environmental problems today are mostly caused by secondary side-effects of our controlling (individually and collectively). Perhaps the greatest problem with side-effects is that control systems do not naturally control or even pay any attention to them.

Collective control (Collective control is a large but not so much studied problem area in PCT which is perhaps best mapped in $[38,39])$ can be loosely defined as a situation where the (primary or secondary) side-effects of the control of some controllers affect the control of some other controllers. Actually, all that which we call "social" consists of collective control. We can differentiate two ideal typical forms of collective control: cooperative and conflictual. An extreme example of cooperative collective control is hierarchical cooperation among individual control units inside a single organism or among individual organisms in a strict bureaucracy-be it a human organization or a nest of social insects. Generally, in cooperative control the side-effects of the controllers benefit the control of other controllers-reciprocally. For example, the use of language is, of course a very important case of collective control $[39,40]$.

Conflictual collective control is in contrast to cooperative control. In conflictual collective control the side-effects of some controllers prevent or hinder the control of other controllers. The conflict-especially in certain mild cases - need not be very harmful and can even be beneficial. It often just forms temporarily frozen situations where the control does not succeed well, and these situations can (in the more fortunate cases) lead to reorganization and solutions to the problem. For example, conflicts between educator and educatee are very typical phases and even intentional tools in promoting the learning of the educatee. In a democratic society the conflicts between parties usually produce a compromised stable situation, which is often not what anybody exactly wants, but which, nevertheless, enables the continuation of the life and the action of the members of the society. 
On the other hand, conflict can also be very harmful and even fatal. In principle, when an error signal remains strong in a control system, the system then tends to increase its output as much as it can. When the other part of the conflict does the same, the conflict escalates slowly or quickly, consuming all the energy available and finally leading to destruction of one or both conflicting systems. A terrifying example, on the global scale, is the arms race. Interestingly this same phenomenon can appear even inside the hierarchical cooperative control of a single human being: A hierarchically higher-level control unit can erroneously send inconsistent reference signals to a lower level, so that these lower units start to control in opposite directions. A typical example could be when someone wants to be both respected and loved and, consequently, tries to behave arrogantly and friendly at the same time. These contradictory goals lead to discontent, waste of internal energy, bad feeling and finally depression. According to a PCT-based psychotherapy view called Method of Levels (MoL), all significant psychical disorders which can be helped by therapy are caused by this kind of internal conflict (see [41,42]).

In fact, MoL is the first area in PCT where we can encounter and consider consciousness concretely. Theoretically, it is quite unclear how the reorganization processes in the nervous system can find the places where learning and repair is needed. Even though it is probable that slow reorganization takes place all the time and everywhere, it is very important that the already well-functioning parts of the system are not radically changed. With experience, the creators of MoL found out that consciousness can direct reorganization just there where it is needed - an idea which not totally unknown in many other therapy traditions. Often, however, the self-help of psychical problems does not lead to a successful outcome but, rather, worsens the situation because the problem is naturally experienced in the control units which are in conflict. However, these units are not the cause of the problem: in fact, they work just as they should. The art of the therapist is to help the client find the hierarchically higher unit-the controlled perception-which is sending the inconsistent references to the lower, and consequently conflicting, units. When that point is found, the client must just keep her consciousness there-or keep it in her consciousness - and the problem will soon resolve themselves as the natural reorganization process changes the adjustments to a new position (pp. 54-55 in [42]). This astonishing phenomenon, that consciousness can so easily and quickly solve internal problems, is-I think - the key to the secret or the mystery of consciousness. At least it offers a suggestion for the adaptive advantage which explains the evolutionary development of consciousness and, at the same time, offers a hint to how that advantage in realized.

\section{Consciousness and Free Will Revisited}

It is quite clear that the fine hierarchical nerve-based control system is required not only for the skillful and adaptive action of humans and animals but also for the development and appearance of consciousness-qualia. Moreover, it seems probable that different kinds of consciousness can be connected to different kinds of control systems. It is possible that animals do have consciousness, but their qualia are certainly different from ours. As Nagel famously supposed, there is something that it is like to be a bat and it is different from what it's like to be a human [43]. Yet, there are no qualia in such hierarchical control system that we have considered so far. Why? Because the perceptual signal that the input function creates-despite being combined from many sources-is always just one scalar value. There are no qualitative differences between these perceptions, and there does not even need to be. For skillful control, these purely quantitative values, differences, and variances are all that is needed. As we can discover, most activities which a human being is doing in its everyday life are done without consciousness; and if consciousness is occasionally connected to them, then their flow will often be not so skillful anymore. In this sense, we all are temporary and partial zombies (Oliver Sacks gives touching examples of the sickness-generated, post-encephalic "zombies" in [44] (e.g., p. 10). I think that after reading that book, Chalmers would perhaps not claim that we could not recognize a zombie on meeting one). 
In the hierarchical control system, every control unit controls its own perception. All these enormous amounts of control actions take place in a coordinated manner, because the references of every unit are determined by some higher units in the hierarchy (The references of the highest units are naturally not determined by still higher units but are instead assumed to be relatively fixed and developed during the life history of the organism). Because every perception - and also every reference-is just a quantitatively variable scalar signal, there cannot be any qualia or other conscious phenomena connected in them. Every perception, as such, is similar or different in relation to another perception quantitatively: it can be more, or less, or as much. A quale as a conscious experience (In conformity with common parlance in PCT discussions, I will use the term conscious experience to differentiate from nonconscious perceptions of the control system. When I use plain experience, I hope the context makes it clear whether it means a nonconscious experience considered in Section 3 or conscious experience meant here) requires first that it has a qualitative content which is similar or different in relation to another experienced quale, both quantitatively and qualitatively. If the conscious experience is based on the perceptions, as it is reasonable to assume, then to the quantitative character of the perception must somehow be added a qualitative character. Where would that character come from? Contrary to perceptions (perceptual signals), there are certain qualitative differences between the control units. The most important qualitative difference between them is based on their respective topological situations in the whole hierarchical structure. This topological situation determines the special function of every control unit in the whole hierarchy and in the action of the organism. Thus, one quale could be based on the strength and situation of one perception.

Secondly, at least our familiar human conscious experiences contain seldom, or perhaps never, just one quale or one property (like plain blueness) but many of them in an organized structure. This organized structure contains, in addition to one or more properties, one or more objects as beings which have those properties (like the sky). We normally experience the properties as properties of something. In addition, there is the structure of focus and periphery: some properties of some objects are in the forefront of our focus (with more or less attention) and other properties of other objects are experienced more dimly as a background. So it seems that consciousness must be realized by some instance in the brain which is able to gather a collection of perceptions from the control hierarchy, attach a special qualitative character to each of them in accordance with their respective situations in the hierarchy, and finally organize them in object and property, focus and periphery, and other possibly relevant structures. The result of this processing is then experienced as an image which represents the reality in the environment—or rather represents itself to be that environment.

What is then the role and function of consciousness? We have a well-functioning, nonconscious control system, which perceives and controls the environment so that our selfpreservation can proceed. Why, then, do we need in addition the separate consciousness system? As Bernard Baars also has stressed in his cognitive theory of consciousness, consciousness is needed for learning something new [45]. It has developed to manage the new and strange situations where the already well-organized competences cannot in their unconscious way take care of problem solving - and there is no time to wait for the slow basic trial-and-error, here-and-there reorganization process or the still much slower process of evolution. Consciousness is then not a homunculus-a miniature copy of oneself-inside a human being but an edunculus, an internal teacher. This idea is also supported by the etymological connection between consciousness and conscience: the idea that the evolutive adaptive function of consciousness seems to keep watch over the action of the control system and intervenes somehow when something does not work as it should.

Powers states: "What you're experiencing is not the object outside of you, but a set of neural signals representing something outside of you." (p. 21 in [46]) The experience here means, naturally, conscious experience. This formulation allows a funny interpretation where "you" is some special instance, perhaps a homunculus, inside you. Rather, it should 
be thought that "you" is you as a whole, containing both conscious and unconscious systems, actions, and experiences. Now, inside of us must be something which realizes conscious experience and that something is a different thing than the homeostatic and perceptual control systems-even though these all must be tightly connected. Taylor presents an interesting and quite credible idea that in addition to hierarchical homeostatic and perceptual systems there exists still a third hierarchical system which he calls logical [30]. It is generally thought in PCT, as Powers theorized, that the perceptual control hierarchy is divided into qualitatively different levels like (from bottom up) intensities, sensation, configurations, transitions, events, relationships etc. (pp. 144-147 in [46]). This nice theory is, however, a little problematic insofar as every level of control hierarchy must be assumed qualitatively indistinguishable. Taylor's view offers a possibility that these named "levels", which all are actually very much like traditional metaphysical categories, are distinguished and determined in the separate conscious logical control system (A comparison of traditional philosophical category systems (see [47] with PCT levels of perception and especially to Dewart's category theory (pp. 140-148 in [4]; pp. 450-456 in [1]) would be an extremely interesting separate research topic).

A quale, like blueness (of the evening sky) or pain (of cramped muscles), is at the same time a perception (either perceived or imagined), a concept or category and a special feeling. I think that, similar to the way every control unit in the perceptual control system represents or rather is a perception created in sense organs and refined in the hierarchical input functions, the units in the logical control system are conscious perceptions refined from the unconscious perceptions of the previous system. How can a logical control unit know what are the unconscious perceptions from which it refines its conscious perception and how that perception should feel? This is possible only because the logical unit must "know" in what positions of the hierarchy those perceptions reside. The unconscious perceptual hierarchy is the map of reality to conscious perceptions. Jake Quilty-Dunn has developed a generative theory of concepts according to which a concept is a generative pointer to those memory locations where the information which forms the content of that concept are stored [48]. Similarly, a logical perception—a category, a quale-is a pointer to certain perceptions and connected memories. If there are also word perceptions connected to that pointer, then it can be a proper concept; but even without words, as is the case with animals, they are just categories. Yet, one may ask: What accounts for these subjective qualitative feelings, which for some is the core of the "hard problem" of consciousness? Simply, because these logical perceptions must be distinguished from each other, they must have some consequences. The unconsciously-controlled perceptions cause the control behavior as their consequences, whereas the logical perceptions do not, because they are just for thinking - and reorganization. So, the different internal feelings connected to different categories are the only way to recognize and differentiate them (Metaphorically, these categories / qualia can be thought of as an internal (and private?) language. According to Saussurean linguistics, the relationship between signifier or expression and signified or content can be thought at least partially arbitrary [49]. This means that your quale feeling of the blueness of the sky can be very different from my respective quale feeling).

Finally, what about free will? Does consciousness offer us that? As we saw with causal relations in Section 4, it is possible to think that even though the world usually functions in a predictable and reliable way, it still does not need to be deterministic, and we all can act in our own ways, whatever the conditions. However, can we consciously direct our action or does consciousness always just watch or, if act, acts late -just as Libet [50] tried to demonstrate? Kahneman has made the famous distinction between fast and slow thinking [51]. We could apply this distinction such that the unconscious perceptual control system is fast-zombies are quick - but the logical system is slow. Thus, consciousness perhaps really tends to be often late-as, for example, with conscience appearing only after the offence has occurred. However, this does not mean that conscience is only a helpless epiphenomenon. It can direct future actions to avoid the mistakes made the in past. This it can do in a very strong way by causing the control system to reorganize in 
a new way. Thirdly, it can try to solve problems of action beforehand-by planning-if only given the time for that. The last word about free will, however, must be given to Strawson [52]: We cannot be ultimately free, because we act and think as ourselves and we are what we are-we cannot change our past history and create ourselves ex nihilo (The structure of the logical system is presumably also hierarchical, and nothing in the hierarchy can purposively determine the references of the highest levels. So, the in-depth transformation of a personality or basic goals of a subject is always a random process). And of course, in addition to this principal restriction, there are much more practical restrictions to anybody's freedom. The whole functional structure drafted in this Section is depicted in Figure 4.

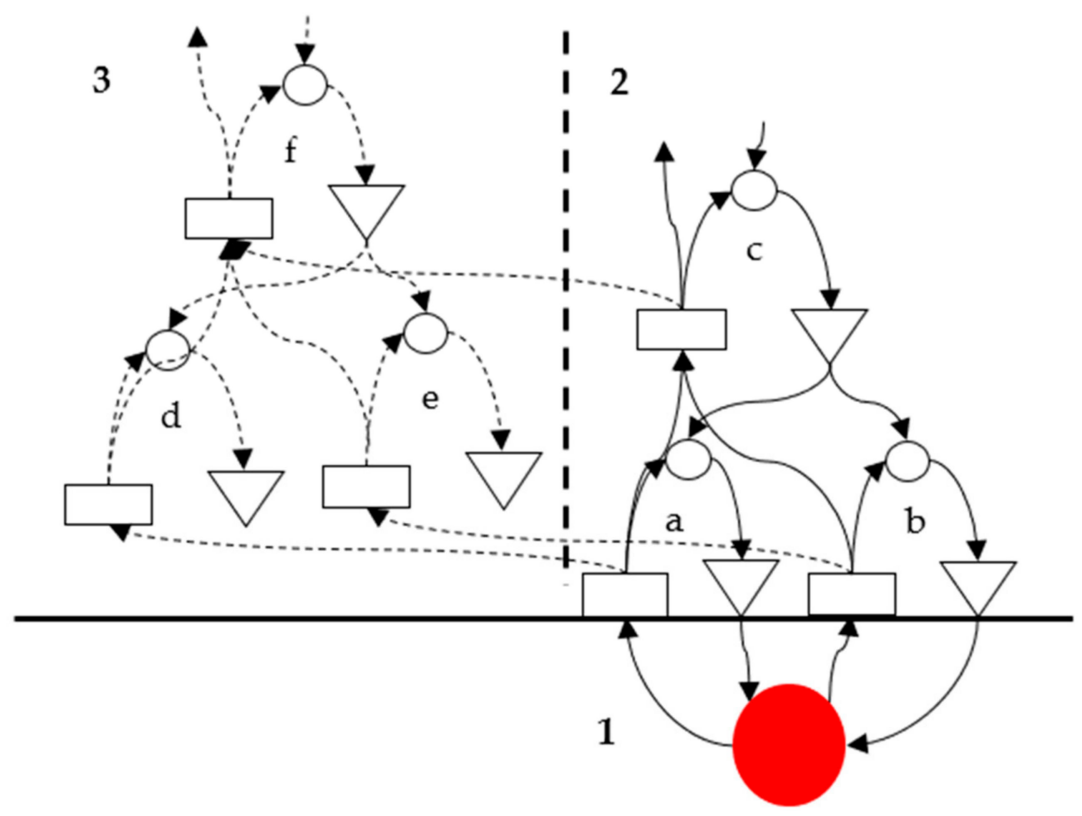

Figure 4. A simplified outline of the functional place of consciousness parallel to (or in the side of) the perceptual control system. Only the basic idea is given here, using only minimal three-unit samples of both systems. 1. In the environment is an object, a "red-ball-being" which affects two input functions of an organism. 2. In the perceptual control system, the control unit a perceives (and possibly controls) a reddish color perception and $\mathbf{b}$ perceives a spherical form perception. The unit c combines these perceptions. If the organism happens to want to perceive a red ball, then $\mathrm{c}$ sends positive reference signals to $\mathbf{a}$ and $\mathbf{b}$. $\mathbf{3}$. In the logical control system, the unit $\mathbf{d}$ recognizes the category of redness, and the unit $\mathbf{e}$ the category of sphericalness, and the unit $\mathbf{f}$ the category of "red balls". All these recognitions evoke a certain own kind of feeling in the organism. The logical system can be much more flexible than the perceptual system, because it is not tied in the interaction with the environment and so it can easily produce new combinations of categories. The feedback effects from logical system to perceptual control systems are not drawn, because they probably affect mainly via still one more different system-namely, the reorganization system. This reorganization system just accelerates the continuous changes in the connections and functions of the control units.

\section{Conclusions: Education as Negative Feedback}

First, an epistemological consideration is in order. For Dewart representationism (Uriah Kriegel [53] analyses the contemporary philosophical theories of consciousness in the Western analytic tradition. The three main theories that he regards as scientifically fruitful are representationalism, higher order monitoring theory and self-representational theory. Actually, these all are representational or representationistic, so that if, in the first instance, the mental representation takes place in the right manner (e.g., intentionally, non-conceptually, abstractly and poised), then it is conscious. In the second instance, the representation becomes conscious if it is represented in a higher order representation; 
and in the third, if the representation somehow represent also itself) was one of the worst faults of modern thinking. The historical root of representationism is the antique (Aristotelian or Hellenistic) idea that the intelligible contents, for example forms and essences, somehow copy themselves into human cognition. Instead, he stresses that reality does not tell us what it is; rather, we assert it first in our experience and then specially in our thematic speech, which then made the development of human consciousness indispensable. The modified Powersian view I presented above is, in a way, doubly presentationist: First, the environment-or rather certain quantitative properties in it-is represented as purely quantitative nerve signals in the hierarchical network of unconscious perceptual control units. These non-qualitative perceptions are then represented in consciousness as qualitative categorical representations or qualia, which feel like something. Thus, the quale of the "blueness of a sky" is not the blueness of the sky and not even a representation of it, but an unstructured symbol referring to the earlier internal consequences of the subject's trials to control her perceptions which had something to do with what we call blue sky (The problem of representationism is not that conscious mental content somehow represents something in the environment but that the process how this representative relation is created is assumed to be too simple and straightforward. In the Aristotelian view, the forms of the reality are copied to the mind. In this kind of view the hard work of consciousness and other cognitive machinery is forgotten. Kantian epistemology took a big step forward but remained still defective especially because it forgot the practical activity, the operative side of competence, and, in consequence, began to disparage the role of reality).

This means that our knowledge and the truth of our assertions about reality is always insecure, restricted, and partial, even though we are concretely in touch with it. We can never know what the ultimate nature or essence of reality is, but we can get-through trials and errors in control- more and more information how reality behaves. However, even this knowledge is at bottom insecure and reinterpretable. Because of this condition, there will always be room and need for philosophy and even metaphysics, in future [54], without forgetting what Dewart strongly underlined: "the philosophical responsibility to remain within the boundaries of empirical findings while keeping the power of reasoning under sensible control. [55]" This is the rule I have tried to obey in these speculations.

To recap, I have assumed that consciousness is realized as a competence in, or around, the logical control system which processes categories i.e., particularized mental representations or perceptions of something as something in some context (The neuronal functional process of how discreet categories are processed from continuous variations is described in [30]). The special benefit of this competence is that it enables imagination, planning and choosing between possible alternatives. This is the competence we have to assume in at least what are considered higher animals, possibly also in simpler forms, and perhaps in all animals. In humans these categories can, furthermore, be connected to words-which are of course also perceptions-which can be controlled: in other words, perceived and produced (Words and other expressions are perceptions which can be perceived when expressed and controlled by expressing. Familiar expressions, which are already reorganized in the control system, can be perceived and controlled nonconsciously, but new and strange expressions require conscious processing).

What, then, has all this to do with education? I believe we can draw two kinds of conclusion in relation to education. In the introduction I stated that the task of the philosophy of education is, on the one hand, to try to analyze what kind of action education is. This topic contains, in particular, the interesting question of how an educator acts-and how she possibly should act. On the other hand, some light should be thrown on the aims and goals of education. Of course, the space and time restrictions prevent any detailed considerations of methods, contents and aims of education in this article.

Education is a form of collective control, and as control it is a case of negative feedback. An external teacher ought to act similarly as an internal teacher-consciousness-namely, monitor and try not to disturb when things go as they should and intervene when necessary. This basic and self-evident starting point is perhaps difficult to remember and accept in 
these times of fashionable, positive psychology and positive pedagogy. Of course, this does not mean that teachers should be cruel and nasty-as they perhaps often have been. Quite the contrary, when things go well the teacher must earn confidence and credibility by being helpful and friendly. This is much needed when things go wrong, and the direction of events must be changed by fair means or by force. Then the teacher must cause a disturbance in the technical sense of control theory. Usually that will not yet help much because from such actions two unfortunate consequences can occur. Either the conflict will escalate, and things happen that no one wishes for, or the student will reorganize but learn something not so hoped for, for instance, cheating. Ideally, the teacher can cooperate with the internal teacher of the student, but that requires that considerable prior learning has taken place and that the teacher can motivate the students. If this cooperation is successful, then the student starts to study, which is equivalent to teaching oneself (This negativity as a basic character of education is perhaps more intelligible in the continental tradition starting with the post-Kantian pedagogical paradox [56-58] and it is exceptionally explicitly reflected by Dietrich Benner in $[59,60])$.

Finally, what about the contents and aims of education, or Bildung as this conceptual whole can be named according to the continental tradition? This concept, which has no exact translation to English (see [61]), but it could be technically defined as acquiring those competences which are good, beneficiary, and required for human living in human society. These competences contain, of course, a vast, historically developing and changing collection of knowledges and skill; more important, however, is whether there is some stable and necessary content. From Dewart we can learn that the core of the specific character of the human species is human consciousness, which develops from the animal form of consciousness as a consequence of speech or assertive thematic communication. As already well-established, human language offers fantastic tools for individual and collective conscious reflection, inference, and direction of action [62]. However, that development process is not automatic and not unproblematic but can mislead or make absent-minded. The fact that children learn to speak so early sets an onerous responsibility on parents, but luckily something can be done also later. According to Dewart, it is the task of philosophy to study and teach us to understand the nature of human consciousness and thus gradually rid ourselves of absent-mindedness.

In this article I have tried to promote the understanding of consciousness-and education-from the starting points of perceptual control theory. The main initial finding of this study is perhaps that while the hierarchical perceptual control system based on the phenomenon of negative feedback realizes the external action of humans and animals, consciousness as internal action takes place on a different, but functionally probably quite similar and strongly-connected, logical control system. The development and learning in both take place via reorganization, which corrects the appearing misfunctions, and these misfunctions will appear only when these systems are used. What makes this consciousness specifically human, is, on one hand, the added efficiency caused by use of language and, on the other, the added need for self-understanding caused by the complex and problematic conditions of human living. By these problematic conditions of human living, I mean the self-caused-via side-effects-problems in social and environmental relations. Every new solution is bound to create new problems.

For Dewart absent-mindedness meant basically that we do not understand that we are conscious and thus do not take responsibility for conscious action (And thus, also the action of consciousness. Here is a strong and interesting parallel connection to the philosophy of Fichte, which, however, must be bypassed in this article (see more in $[13,63])$ ). I would concretize this view by adding that an important part of absent-mindedness is that we do not take responsibility for the side-effects of our actions. This responsibility requires, of course, that we can know and perceive the side-effects and their consequences. This is, as we have seen, an unnatural requirement for a simple control system, because it perceives only what it controls-and controls what it perceives. The control of side-effects requires recruiting extra control units for it and this has its costs. Of course, ideally the side-effects 
could be anticipated beforehand, and this requires a lot of knowledge and planning in consciousness before any action is taken. The control of the side effects and all that is required is painful and resource consuming, and thus requires a lot of motivation and reorganization. A central reason for controlling side-effects is to avoid harmful conflicts. A good motivation for avoiding conflicts is shown by PCT, which offers good scientific grounds for the utility of the age-old ethical principle called "the golden rule" [64].

Learning is valuable, but much more important for education is the question of what should be learned and how [65]. Education seen as just promoting learning is as such a proof of absent-mindedness, just as freedom seen as absence of obligations. Learning is not just adding new handy skills and knowledge but part of total reorganization of the learner and consequently of the society and the world.

Funding: This research received no external funding.

Institutional Review Board Statement: Not applicable.

Informed Consent Statement: Not applicable.

Data Availability Statement: Not applicable.

Acknowledgments: First I must thank Timo Järvilehto for advising me to take a look at Dewart's Evolution and Consciousness already in the nineties; unfortunately, I did not manage to properly read it until during this Corona year. I am especially thankful to Dewart's mentee and collaborator, Greg Nixon, for his discussions and materials. I also thank Andy Stables for inviting me to write for this special issue and for his continued discussion and support within the semiotics of education, and, not least, Martin Taylor for mentoring me within Perceptual Control Theory.

Conflicts of Interest: The author declares no conflict of interest.

\section{References}

1. Deward, L. Hume's Challenge and the Renewal of Modern Philosophy; BookBaby: Pennsauken Township, NJ, USA, 2016.

2. Wallace-Wells, D. The Uninhabitable Earth: Life after Warming; Tim Duggan Books: New York, NY, USA, 2019.

3. Humphreys, C.; Blenkinsop, S. White Paper Concerning Philosophy of Education and Environment. Stud. Philos. Educ. 2017, 36, 243-264. [CrossRef]

4. Dewart, L. Evolution and Consciousness: The Role of Speech in the Origin and Development of Human Nature; University of Toronto Press: Toronto, ON, Canada, 1989.

5. Pikkarainen, E. The Semiotics of Education: A new vision in an old landscape. Educ. Philos. Theory 2010, 43, 1135-1144. [CrossRef]

6. Pikkarainen, E. Competence as a Key Concept of Educational Theory: A Semiotic Point of View. J. Philos. Educ. 2014, 48, 621-636. [CrossRef]

7. Powers, W.T. Behavior: The Control of Perception; Benchmark Publications: New Canaan, CT, USA, 2005.

8. Greimas, A.J.; Courtés, J. Semiotics and Language: An Analytical Dictionary; Indiana University Press: Bloomington, IN, USA, 1982.

9. Sawa, R.; Tarver, W.T.S. Leslie Dewart. In The Palgrave Handbook of Radical Theology; Rodkey, C.D., Miller, J.E., Eds.; Palgrave Macmillan I Springer Nature: Cham, Switzerland, 2018; pp. 171-185.

10. Savage, A.M. Leslie Dewart (1922-2009): Canada's Forgotten Theological Philosopher; D.I.M. Publisching: Rotterdam, The Netherlands, 2020.

11. Khan, A.H.; Alton, B.; Meynell, H.; Wiebe, D.; Dewart, L. Leslie Dewart's Evolution and Consciousness: Three commentaries. Stud. Relig. Sci. Relig. 1991, 20, 75-102. [CrossRef]

12. Henrich, D. Self-consciousness, a critical introduction to a theory. Man World 1971, 4, 3-28. [CrossRef]

13. Henrich, D. Fichte's Original Insight. In Contemporary German Philosophy; Christensen, D.E., Ed.; Pennsylvania State U.P: University Park, PA, USA, 1982; Volume 1, pp. 15-53.

14. Stables, A. Living and Learning as Semiotic Engagement: A New Theory of Education; Edwin Mellen Press: Lewiston, UK, 2005.

15. Strawson, G. A hundred years of consciousness: "a long training in absurdity". Estud. Filos. 2019, 59, 9-43. [CrossRef]

16. Chittka, L.; Wilson, C. Expanding Consciousness. Am. Sci. 2019, 107, 364-369. [CrossRef]

17. Wilson, C. Consciousness as a Biological Phenomenon. Harv. Rev. Philos. 2018, 25, 71-87. [CrossRef]

18. Strawson, G. Consciousness Isn't a Mystery: It's Matter. 2016. Available online: https://www.nytimes.com/2016/05/16 /opinion/consciousness-isnt-a-mystery-its-matter.html (accessed on 30 November 2020).

19. Chalmers, D.J. The Conscious Mind: In Search of a Fundamental Theory; Oxford University Press: New York, NY, USA, 1996.

20. Peters, F. Consciousness Should Not Be Confused with Qualia. Logos Epistem. 2014, 5, 63-91. [CrossRef]

21. Polger, T.W. Zombies. In Oxford Companion to Consciousness; Bayne, T., Cleeremans, A., Wilken, P., Eds.; Oxford University Press: Oxford, UK, 2009; pp. 671-674. 
22. Heil, J. From an Ontological Point of View; Clarendon Press: Oxford, UK, 2003.

23. Strawson, G. Realistic Monism: Why Physicalism Entails Panpsychism. In Real Materialism; Strawson, G., Ed.; Oxford University Press: Oxford, UK, 2008.

24. Strawson, G. The Mary-Go-Round. In The Knowledge Argument; Coleman, S., Ed.; Cambridge University Press: Cambridge, UK, 2019; pp. 118-140.

25. Goff, P.; Seager, W.; Allen-Hermanson, S. Panpsychism. In The Stanford Encyclopedia of Philosophy (Summer 2020 Edition); Zalta, E.N., Ed.; Metaphysics Research Lab: Stanford, CA, USA, 2020. Available online: https://plato.stanford.edu/entries/panpsychism/ (accessed on 30 November 2020).

26. Nida-Rümelin, M.; Conaill, O.D. Qualia: The Knowledge Argument. In the Stanford Encyclopedia of Philosophy (Winter 2019 Edition); Zalta, E.N., Ed.; Metaphysics Research Lab: Stanford, CA, USA, 2019. Available online: https://plato.stanford.edu/entries/ qualia-knowledge/ (accessed on 30 November 2020).

27. Strawson, G. What does "physical" mean? A prolegomenon to panpsychism. In The Routledge Handbook of Panpsychism; Seager, W., Ed.; Routledge: New York, NY, USA, 2019; pp. 317-339.

28. Chalmers, D.J. The Combination Problem for Panpsychism. In Panpsychism; Jaskolla, L., Bruntrup, G., Eds.; Oxford University Press: New York, NY, USA, 2016; pp. 179-214.

29. Nixon, G.M. Hollows of Memory. J. Conscious. Explor. Res. 2010, 1, $213-401$.

30. Taylor, M.M. Powers of Perceptual Control: An Inquiry into Language, Culture, Power, and Politics; Unpublished Manuscript; 2020.

31. Powers, W.T. The origins of purpose: The first metasystem transitions. World Fut. 1995, 45, 125-137. [CrossRef]

32. Munis, J.R. Just Enough Physiology; Oxford University Press: New York, NY, USA, 2012.

33. Hall, J.E.; Hall, M.E. Guyton and Hall Textbook of Medical Physiology, 13th ed.; Elsevier: Philadelphia, PA, USA, 2016.

34. Serres, M. Hermes: Literature, Science, Philosophy; Johns Hopkins University Press: Baltimore, MD, USA, 1983.

35. Damasio, A. Self Comes to Mind: Constructing the Conscious Brain; Pantheon/Random House: New York, NY, USA, 2010.

36. Powers, W.T. Living Control Systems III: The Fact of Control; Benchmark Publications: Bloomfield, NJ, USA, 2008.

37. Pfau, R.H. Your Behavior: Understanding and Changing the Things You Do; Paragon House: Saint Paul, MN, USA, 2017.

38. McClelland, K. Social structure and control: Perceptual control theory and the science of sociology. In The Interdisciplinary Handbook of Perceptual Control Theory: Living Control Systems IV; Mansell, W., Ed.; Academic Press: London, UK, 2020; pp. 229-297.

39. Taylor, M.M. Perceptual control in cooperative interaction. In The Interdisciplinary Handbook of Perceptual Control Theory: Living Control Systems IV; Mansell, W., Ed.; Academic Press: London, UK, 2020; pp. 299-350.

40. Nevin, B. Language and thought as control of perception. In The Interdisciplinary Handbook of Perceptual Control Theory: Living Control Systems IV; Mansell, W., Ed.; Academic Press: London, UK, 2020; pp. 351-459.

41. Mansell, W.; Carey, T.A.; Tai, S.J. A Transdiagnostic Approach to CBT Using Method of Levels Therapy; Routledge: London, UK, 2012.

42. Carey, T.A. The Method of Levels: How to Do Psychotherapy without It Getting in the Way; Living Control Systems Publishing: Hayward, CA, USA, 2006.

43. Nagel, T. What Is It Like to Be a Bat? Philos. Rev. 1974, 83, 435-450. [CrossRef]

44. Sacks, O. Awakenings; Random House, Inc.: New York, NY, USA, 1999.

45. Baars, B.J. A Cognitive Theory of Consciousness; Cambridge U.P.: Cambridge, MA, USA, 1988.

46. Powers, W.T. Making Sense of Behavior: The Meaning of Control; Benchmark Publications: Montclair, NJ, USA, 1998.

47. Thomasson, A. Categories. In The Stanford Encyclopedia of Philosophy (Summer 2019 Edition); Zalta, E.N., Ed.; Metaphysics Research Lab, Stanford University: Stanford, CA, USA, 2019.

48. Quilty-Dunn, J. Polysemy and thought: Toward a generative theory of concepts. Mind Lang. 2021, 36, 158-185. [CrossRef]

49. Saussure, F.D. Course in General Linguistics; Duckworth: London, UK, 1983.

50. Libet, B. Unconscious cerebral initiative and the role of conscious will in voluntary action. Behav. Brain Sci. 1985, 8, 529-539. [CrossRef]

51. Kahneman, D. Thinking, Fast and Slow; Penguin Books: London, UK, 2011.

52. Strawson, G. Free agents. In Real Materialism and Other Essays; Strawson, G., Ed.; Clarendon Press: Oxford, UK, 2008 ; pp. 359-386.

53. Kriegel, U. Philosophical theories of consciousness: Contemporary Western perspectives. In The Cambridge Handbook of Consciousness; Zelazo, P., Moscovitch, M., Thompson, E., Eds.; Cambridge University Press: Cambridge, UK, 2007 ; pp. 35-66.

54. Stein, H. How does physics bear upon metaphysics; and why did Plato hold that philosophy cannot be written down? Stud. Hist. Phil. Mod. Phys. 2020, 72, 152-161. [CrossRef]

55. Nixon, G.M. Response to L. Dewart's Commentary 5 on TA-95. 2007. Available online: https://web.archive.org/web/20071218 071039/http:/ kjf.ca/95-R5DEW.htm (accessed on 20 November 2020).

56. Kukkola, J.; Pikkarainen, E. Edusemiotics of meaningful learning experience: Revisiting Kant's pedagogical paradox and Greimas' semiotic square. Semiotica 2016, 2016, 199-217. [CrossRef]

57. Kivelä, A. Kantin pedagoginen paradoksi. Nuorisotutkimus 2002, 20, 45-60.

58. Uljens, M. The Pedagogical Paradox and the Problem of Subjectivity and Intersubjectivity. 2001. Available online: https: //pesa.org.au/images/papers/2001-papers/uljens-michael-subjectivitiy.pdf (accessed on 10 November 2020).

59. Benner, D.; English, A. Critique and Negativity: Towards the Pluralisation of Critique in Educational Practice, Theory and Research. J. Philos. Educ. 2004, 38, 409-428. [CrossRef] 
60. Benner, D. Einleitung. Über pädagogisch relevante und erziehungswissenschaftlich fruchtbare Aspekte der Negativität menschlicher Erfahrung. Z. Pädag. 2005, 49, 7-23.

61. Siljander, P.; Kivelä, A.; Sutinen, A. (Eds.) Theories of Bildung and Growth: Connections and Controversies between Continental Educational Thinking and American Pragmatism; Sense Publishers: Rotterdam, NL, USA, 2012.

62. McCrone, J. A bifold model of freewill. J. Conscious. Stud. 1999, 6, 241.

63. Garcia, L.F. Knowing, Creating and Teaching: Fichte's Conception of Philosophy as Wissenschaftslehre. Fichte Stud. 2018, 46, 249-267. [CrossRef]

64. Pfau, R. Can We Control the Behavior of Others or Only Influence It? PCT, Interpersonal, and Other Perspectives. In Proceedings of the International Association for Perceptual Control Theory Conference, Evanston, IL, USA, 12-13 October 2018.

65. Peltonen, J. Schools and the new language of learning: A critical perspective. In Schools in Transition: Linking Past, Present, and Future in Educational Practice; Siljander, P., Kontio, K., Pikkarainen, E., Eds.; Sense Publishers: Rotterdam, NL, USA, 2017; pp. 67-78. 